\title{
Multidisciplinary rehabilitation and steroids in the management of multiple sclerosis relapses: a randomized controlled trial
}

\author{
Una Nedeljkovic ${ }^{1}$, Jelena Dackovic ${ }^{2}$, Darija Kisic Tepavcevic ${ }^{3}$, Irena Dujmovic Basuroski², \\ Sarlota Mesaros ${ }^{2}$, Tatjana Pekmezovic ${ }^{3}$, Jelena Drulovic ${ }^{2}$
}

${ }^{1}$ Clinic of Physical Medicine and Rehabilitation, Clinical Center of Serbia,
Faculty of Medicine, University of Belgrade, Belgrade, Serbia
${ }^{2}$ Clinic of Neurology, Clinical Center of Serbia, Faculty of Medicine,
University of Belgrade, Belgrade, Serbia
${ }^{3}$ Institute of Epidemiology, Faculty of Medicine, University of Belgrade, Belgrade, Serbia

Submitted: 19 July 2014

Accepted: 18 September 2014

Arch Med Sci 2016; 12, 2: 380-389

DOI: 10.5114 /aoms.2015.47289

Copyright $\odot 2016$ Termedia \& Banach

\begin{abstract}
Introduction: Periodic relapses are one of the main characteristics of multiple sclerosis (MS), from which recovery is often incomplete despite highdose methylprednisolone (HDMP) treatment. The aim of our study was to evaluate the potential benefits of short-term HDMP combined with multidisciplinary rehabilitation (MDR) in persons with MS in relapse in order to assess whether combination of steroid therapy with MDR is more beneficial than steroid therapy alone.

Material and methods: This investigation was conducted as a randomized controlled trial. The MS patients were eligible if they had an established diagnosis and relapse requiring application of HDMP. Forty-nine patients were included in the study and randomized to control and treatment groups, and 37 completed the study. High-dose methylprednisolone was administered to all patients. The treatment group additionally underwent an MDR program over a 3-week period. All outcome measures were completed at baseline and 1 and 3 months later.

Results: The Expanded Disability Status Scale (EDSS) and Functional Independence Measure (FIM) motor scores improved statistically significantly 1 month after HDMP, in both treatment and control groups. During the study period, in the treatment group, a sustained large effect size (ES) was found for both physical and mental composite scores of Multiple Sclerosis Quality of Life-54 (MSQoL-54), while in the controls, a sustained moderate ES was demonstrated only for physical composite score.
\end{abstract}

Conclusions: Our findings suggest that MDR improves MS relapse outcome.

Key words: multiple sclerosis, relapsing-remitting, relapse, multidisciplinary rehabilitation, randomized controlled trial, methylprednisolone.

\section{Introduction}

Multiple sclerosis (MS) is an inflammatory and neurodegenerative disease of the central nervous system with a heterogeneous and variable clinical course [1]. It has to be emphasized that, apart from disease-modifying therapies, management of relapses, symptomatic drugs and neurorehabilitation have a significant role in the treatment of relapsing MS [2].

\author{
Corresponding author: \\ Una Nedeljkovic MD \\ Clinic of Physical Medicine \\ and Rehabilitation \\ Clinical Center of Serbia \\ Faculty of Medicine \\ University of Belgrade \\ 2 Pasterova St \\ 11000 Belgrade, Serbia \\ Phone: +381641109897 \\ E-mail: unaned@gmail.com
}


Short-term high-dose methylprednisolone (HDMP) therapy is well known to improve symptoms in acute exacerbation of MS and shorten the period of recovery after exacerbation [3-5]. The initial effects occur rapidly, usually within the first week of starting treatment. However, as already mentioned, up to $40 \%$ of relapses may leave some residual problems [6], and there is evidence that improvement of impairments and disability after treatment with HDMP for a relapse of MS occurs early, while improvement of subjective health status is delayed [7]. It has not been fully elucidated yet how HDMP exerts its rapid beneficial effect in patients with MS. Steroids have dual inhibitory and stimulatory effects on various factors of the immune response, through influencing secretion of cytokines and chemokines, reduction of cerebrospinal fluid levels of matrix metalloproteinases (MMP), and increasing levels of tissue inhibitors of MMP, as well as reduction of expression of adhesion molecules, interfering with the blood-brain barrier disruption [8].

Physical therapy has been proposed to counteract many of the consequences of MS [9, 10]. Indeed, evidence indicates that exercise has the potential to improve and/or maintain functional ability, strength, fatigue, health-related quality of life (HRQoL), depression, and cognition, in subjects with MS [11, 12] and other neurological disorders [13]. However, studies dealing with the impact of rehabilitation on the health status of patients with relapsing-remitting MS in relapse are extremely rare $[12,14]$. Therefore, we decided to perform a randomized controlled trial in order to assess, based on objective measures and MSQoL-54, whether combination of multidisciplinary rehabilitation (MDR) with steroid therapy is more beneficial than steroid therapy alone.

The aim of our study was to evaluate the potential benefits of MDR combined with administration of intravenous HDMP in persons with MS in relapse.

\section{Material and methods}

\section{Subjects}

This investigation was conducted as a randomized controlled trial at the Clinical Center of Serbia (CCS) in Belgrade. Eligible patients were selected by neurologists (JD, IDB, JD) at the Clinic of Neurology, CCS, according to the following criteria: a) confirmed relapse requiring application of HDMP in patients with an established diagnosis of relapsing remitting (RR) MS, according to the Revised McDonald criteria [15]; b) admission to the Clinic of Neurology as either a day case or an inpatient; c) age 18 years and above. Patients were excluded if they suffered from dementia, alcoholism, had any serious medical comorbidities or were pregnant. During the study, the participants were excluded if they had an attack.

During a 24-month period (July 1, 2011-July 1, 2013), 49 MS patients were included in the study and randomized to control (20 patients) and treatment (17 patients) groups by simple randomization using a computer-generated list. Eligible patients completed all pre-intervention assessment before randomization. Patients were randomly allocated to the treatment or control group according to the randomization list and informed of their study group. Seven patients (3 from the treatment group and 4 from the control group) dropped out of the study because they had an attack, and 5 patients ( 2 from the treatment group and 3 from the control group) because of the unexpected lack of time. A total of 37 MS patients completed the study.

This study was conducted with approval by the Ethics Committee of the Faculty of Medicine, University of Belgrade, and written informed consent was obtained from all patients.

\section{Intervention}

Treatment patients received $1 \mathrm{~g}$ daily of intravenous methylprednisolone (MP) for 5 days and MDR during steroid therapy and the acute period afterwards for 3 weeks. The treating therapy team individually tailored the rehabilitation program to meet patient needs. This multidisciplinary team comprised neurologists (JD, IDB, JD) and a rehabilitation physician (UN) with expertise in MS management, a physiotherapist, an occupational therapist and a psychologist. Other specialists' input included social services and continence advice, when needed. The patients received individualized physiotherapy in order to improve function through motor learning, by emphasizing the individual's motor control, especially in relation to balance and movement. The multidisciplinary program also included interventions, such as education of patients and caregivers and bladder management techniques for those with continence issues. Advice was given for continuing self-management after discharge. Patients were advised to continue exercising in community settings.

Physical rehabilitation was performed at the Clinic of Neurology and afterwards at the Clinic of Physical Medicine and Rehabilitation, CCS, via the outpatient rehabilitation program. Rehabilitation consisted of 3 weeks of exercise and occupational therapy and was performed by MS specialized physiotherapists. Exercises were performed for $1 \mathrm{~h}$, 5 times a week, and occupational therapy for $30 \mathrm{~min}$, 3 times a week. Motor rehabilitation was arranged as individual physiotherapy. Exercises varied between aerobic training (walk or treadmill), 
muscle stretching, strength training, balance and gait training. Aerobic training was included in each patient's rehabilitation program in order to enhance endurance. Progression of intensity was firstly achieved through prolonging the walking time and later through increasing the velocity, in order to achieve 20 min for a given velocity. Rate of perceived exertion and targeted heart rate were used as indicators for the intensity of training.

Control patients were treated according to the standard ward protocol for intravenous HDMP therapy including 5 days' intravenous MP. Patients were referred for potential subsequent outpatient physical therapy in community settings.

\section{Measurements}

All outcome measures were completed at baseline (the first day of intravenous HDMP), and 1 month and 3 months after the first day of steroid therapy. All questionnaires except the Functional Independence Measure (FIM) [16] were completed by the patients in the presence of a physician, who provided assistance when necessary. Because of the type of the study, neither the patients nor the assessing therapists were blinded.

Outcome measures used were the Expanded Disability Status Scale (EDSS) [17], the Beck Depression Inventory (BDI) [18], FIM [16], and the Serbian version of Multiple Sclerosis Quality of Life-54 (MSQoL-54) [19]. The neurological disability was assessed using EDSS. Scoring was based on neurologic testing and examination of the following eight functional systems: pyramidal (ability to walk), cerebellar (coordination), brain stem, sensory, bowel and bladder functions, visual, mental, and other (including any other neurological findings due to MS).

The Beck Depression Inventory (BDI) was given to each patient to explore feelings and attitudes relating to general depressive status.

The FIM assesses function and need for assistance in 18 items in motor and cognitive domains. Each item is rated on a scale of 1 to 7 ( $1=$ total assistance, 5 = supervision, $7=$ independent), based on the assistance needed for different activities, physical and mental. The maximal score is 126 and minimal 18, with higher scores indicating higher levels of independence. The FIM scores were based on actual performance on a task on a daily basis.

MSQoL-54 includes one of the most widely used quality of life measures, the SF-36, as a generic base, and an additional 18 items specific to MS. The SF-36 items are scored somewhat differently in the context of the MSQoL-54, in that the 54 items of the questionnaire are distributed in 12 multi-item scales and 2 single items. Additionally, two summary scores, the Physical health and Mental health composites, are derived from a weighted combination of scale scores. These scores were created using the Likert method [20], by averaging items within the scales, then row scores were linearly transformed into 0-100 scales, with higher values indicating a better quality of life.

\section{Statistical analysis}

The importance of changes in quality of life scores and clinical characteristics of MS patients between baseline and each follow-up time-point were quantified using the Wilcoxon signed ranks test. The magnitude of any differences for the quality of life changes was calculated as an effect size (ES) (mean follow-up - mean baseline)/ pooled SD) with 95\% confidence intervals. According to Cohen's thresholds, the ESs are categorized as follows: trivial (0-0.19), small (0.20-0.49), medium (0.50-0.79), and large (0.80 and above) effects [21].

The SPSS 17.0 statistical software package (SPSS Inc, Chicago, IL, U.S.A.) was used in the statistical analysis.

\section{Results}

Table I shows demographic and clinical data in the treatment and control groups. There was no difference between groups in any demographic or clinical data except for the educational status, which showed a higher percentage of people with a university degree in the treatment group, which, however, also did not reach statistical significance. Groups did not differ in any of the outcome measures at the beginning of the study.

There was a statistically significant improvement in EDSS scores between baseline and month 1 , sustained between month 1 and month 3, both in the treatment $(p=0.002$, and $p=0.003$, respectively) and control group ( $p=0.001$, and $p=$ 0.026 , respectively) (data not shown). There was also a statistically significant improvement in FIM motor scores between baseline and month 1 , sustained between month 1 and month 3 both in the treatment and control group $(p<0.001)$ (data not shown). In contrast, no change in FIM cognitive scores was detected between baseline and subsequent time points, either in the treatment group or in the controls. A statistically significant improvement in BDI scores between baseline and both follow-up time points was found in the treatment group ( $p=0.001, p=0.020$, respectively), but no change between baseline and any of the subsequent time points was found in the control group (data not shown).

However, no significant changes were detected in the EDSS, BDI, and FIM scores between baseline and 1-month and 3-month follow-up scores, 
Table I. Baseline demographic and clinical characteristics for the treatment and control groups

\begin{tabular}{|c|c|c|c|}
\hline Variable & $\begin{array}{l}\text { Randomized to treatment } \\
\text { group }(n=17)\end{array}$ & $\begin{array}{l}\text { Randomized to control } \\
\text { group }(n=20)\end{array}$ & Value of $p$ \\
\hline Gender: & & & 0.495 \\
\hline Male & $6(35.3)$ & $5(25.0)$ & \\
\hline Female & $11(64.7)$ & $15(75.0)$ & \\
\hline Current age [years] & $41.3 \pm 9.9(22-61)$ & $39.4 \pm 10.7(18-62)$ & 0.583 \\
\hline Education [years]: & & & 0.085 \\
\hline Primary (1-8) & - & $1(5.0)$ & \\
\hline Secondary (9-12) & $6(35.3)$ & $14(60.0)$ & \\
\hline University (13+) & $11(64.7)$ & $5(35.0)$ & \\
\hline Marital status: & & & 0.564 \\
\hline Single (never married) & $4(23.5)$ & $8(40.0)$ & \\
\hline Married/cohabiting & $11(64.7)$ & $10(50.0)$ & \\
\hline Widowed & 0 & 0 & \\
\hline Separated/divorced & $2(11.8)$ & $2(10.0)$ & \\
\hline Current employment status: & & & 0.902 \\
\hline Employed outside the home/student & $10(58.8)$ & $11(55.0)$ & \\
\hline Retired & $4(23.5)$ & $6(30.0)$ & \\
\hline Unemployed & $3(17.6)$ & $3(15.0)$ & \\
\hline Age at onset of MS [years] & $32.5 \pm 9.4(17-51)$ & $32.8 \pm 10.7(16-59)$ & 0.924 \\
\hline Disease duration [months] & $104.5 \pm 90.3(0-314)$ & $80.6 \pm 71.4(6-276)$ & 0.375 \\
\hline EDSS score & $4.5 \pm 1.4(3.0-7.5)$ & $4.0 \pm 0.9(2.5-6.5)$ & 0.195 \\
\hline BDI score & $12.2 \pm 8.9(0.0-36.0)$ & $14.0 \pm 8.3(2.0-32.0)$ & 0.537 \\
\hline FIM motor score & $73.1 \pm 16.1(23.0-88.0)$ & $77.5 \pm 8.2(57.0-89.0)$ & 0.288 \\
\hline FIM cognitive score & $34.6 \pm 0.8(23.0-35.0)$ & $33.7 \pm 2.9(23.0-35.0)$ & 0.228 \\
\hline
\end{tabular}

Results were presented as mean \pm SD (range) or mean (\%). EDSS - Expanded Disability Status Scale, BDI - Beck Depression Inventory, FIM - Functional Independence Measure.

comparing treatment and control groups (Tables II and III). The change scores were calculated by subtracting mean baseline from the mean follow-up score; therefore improvement is indicated by negative scores on the EDSS and BDI, and positive scores on the FIM.

Regarding changes in HRQoL scores, 1 month after MDR, a significant improvement was demonstrated for the Physical role limitations score ( $p=0.015)$ of MSQoL-54, in the treatment group compared with controls (Table IV).

Furthermore, 3 months after MDR, improvements were observed in the treatment group in comparison with the control group, in the following domains of MSQoL-54: Physical role limitations score $(p=0.016)$, Emotional role limitations $(p=0.010)$ and Mental health composite $(p=0.017)$ scores (Table V).
The changes in HRQoL in patients with MS during the 3-month follow-up are presented in Table VI. A statistically significant improvement in the quality of life in the treatment group at each subsequent time point was detected for the following scales of MSQoL-54: Physical health, Physical role limitations, Emotional role limitations, Emotional well-being, Energy, Health perception, Social function, as well as for both Physical health composite and Mental health composite. Additionally, Pain was improved only at 1-month follow-up and Overall quality of life only at 3-month follow-up. In the control group, significant improvement in quality of life domains was demonstrated at both time points only for Physical health, Health perception and for Physical health composite.

In the treatment group, the analysis of magnitude for changes in HRQoL during the entire fol- 
Table II. Clinical change scores from baseline to first month

\begin{tabular}{|lccccc|}
\hline Scales & $\begin{array}{c}\text { Treatment }(N=17), \\
\text { mean } \pm \text { SD }\end{array}$ & $\begin{array}{c}\text { Control }(N=20), \\
\text { mean } \pm \text { SD }\end{array}$ & $\begin{array}{c}\text { Mean } \\
\text { difference }\end{array}$ & $\begin{array}{c}\text { 95\% Cl for } \\
\text { mean difference }\end{array}$ & Value of $p$ \\
\hline EDSS & $-0.9 \pm 1.3$ & $-0.5 \pm 0.6$ & -0.4 & -0.9 to 0.4 & -7.5 to 3.8 \\
\hline BDI & $-3.8 \pm 3.4$ & $-2.0 \pm 11.0$ & -1.8 & -1.4 to 14.4 & 0.518 \\
\hline FIM motor & $+15.6 \pm 16.0$ & $+9.1 \pm 6.4$ & +6.5 & -1.9 to 0.6 & 0.102 \\
\hline FIM cognitive & $0.0 \pm 0.0$ & $+0.7 \pm 2.4$ & -0.7 & 0.284 \\
\hline
\end{tabular}

EDSS - Expanded Disability Status Scale, BDI - Beck Depression Inventory, FIM - Functional Independence Measure.

Table III. Clinical change scores from baseline to third month

\begin{tabular}{|c|c|c|c|c|c|}
\hline Scales & $\begin{array}{c}\text { Treatment }(N=17), \\
\text { mean } \pm \text { SD }\end{array}$ & $\begin{array}{c}\text { Control }(N=20), \\
\text { mean } \pm \text { SD }\end{array}$ & Mean difference & $\begin{array}{l}95 \% \mathrm{Cl} \text { for mean } \\
\text { difference }\end{array}$ & Value of $p$ \\
\hline EDSS & $-1.4 \pm 1.4$ & $-0.9 \pm 0.8$ & -0.5 & -1.3 to 0.3 & 0.184 \\
\hline BDI & $-3.5 \pm 6.2$ & $-2.7 \pm 7.0$ & -0.8 & -5.2 to 3.7 & 0.725 \\
\hline FIM motor & $+15.4 \pm 16.3$ & $+10.3 \pm 6.9$ & +5.1 & -3.1 to 13.2 & 0.217 \\
\hline FIM cognitive & $0.0 \pm 0.0$ & $+0.8 \pm 7.8$ & +0.8 & -3.0 to 4.7 & 0.657 \\
\hline
\end{tabular}

EDSS - Expanded Disability Status Scale, BDI - Beck Depression Inventory, FIM - Functional Independence Measure.

Table IV. Quality of life change scores from baseline to first month

\begin{tabular}{|c|c|c|c|c|c|}
\hline MSQoL-54 & $\begin{array}{c}\text { Treatment }(N=17) \\
\text { mean } \pm S D\end{array}$ & $\begin{array}{l}\text { Control }(N=20), \\
\text { mean } \pm \text { SD }\end{array}$ & $\begin{array}{c}\text { Mean } \\
\text { difference }\end{array}$ & $\begin{array}{l}95 \% \mathrm{Cl} \text { for mean } \\
\text { difference }\end{array}$ & Value of $p$ \\
\hline Physical health & $+14.1 \pm 25.3$ & $+13.5 \pm 16.3$ & 0.6 & -13.4 to 14.6 & 0.929 \\
\hline $\begin{array}{l}\text { Physical role } \\
\text { limitations }\end{array}$ & $+29.4 \pm 40.7$ & $-2.6 \pm 35.4$ & 32.0 & 6.6 to 57.4 & 0.015 \\
\hline $\begin{array}{l}\text { Emotional role } \\
\text { limitations }\end{array}$ & $+23.5 \pm 45.3$ & $+3.1 \pm 42.6$ & 20.4 & -8.9 to 49.8 & 0.167 \\
\hline Pain & $+14.8 \pm 13.1$ & $+10.4 \pm 25.4$ & 4.4 & -9.5 to 18.2 & 0.525 \\
\hline Emotional well-being & $+15.8 \pm 18.9$ & $+10.6 \pm 22.1$ & 5.2 & -8.7 to 19.0 & 0.455 \\
\hline Energy & $+8.5 \pm 14.4$ & $+11.0 \pm 20.5$ & -2.5 & -14.6 to 9.5 & 0.673 \\
\hline Health perception & $+5.0 \pm 9.5$ & $+11.0 \pm 15.8$ & -6.0 & -14.9 to 2.9 & 0.180 \\
\hline Social function & $+11.8 \pm 16.4$ & $+7.9 \pm 19.2$ & 3.8 & -8.2 to 15.9 & 0.521 \\
\hline Cognitive functioning & $+4.1 \pm 18.9$ & $+8.5 \pm 30.9$ & -4.4 & -17.1 to 9.0 & 0.512 \\
\hline Health distress & $+1.5 \pm 15.6$ & $+4.7 \pm 24.3$ & -3.2 & -17.2 to 10.6 & 0.635 \\
\hline Sexual function & $-3.5 \pm 23.2$ & $+4.1 \pm 28.4$ & -7.6 & -25.1 to 9.9 & 0.385 \\
\hline Change in health & $-13.2 \pm 30.8$ & $-15.0 \pm 40.1$ & 1.8 & -22.4 to 25.9 & 0.883 \\
\hline $\begin{array}{l}\text { Sexual function } \\
\text { satisfaction }\end{array}$ & $0.0 \pm 50.0$ & $-7.5 \pm 45.2$ & 7.5 & -24.3 to 39.3 & 0.685 \\
\hline Overall quality of life & $+7.8 \pm 16.5$ & $+4.0 \pm 12.3$ & 3.8 & -5.8 to 13.5 & 0.425 \\
\hline $\begin{array}{l}\text { Physical health } \\
\text { composite }\end{array}$ & $+10.7 \pm 10.2$ & $+8.1 \pm 11.1$ & 2.6 & -4.6 to 9.8 & 0.467 \\
\hline $\begin{array}{l}\text { Mental health } \\
\text { composite }\end{array}$ & $+12.4 \pm 14.1$ & $+6.5 \pm 18.7$ & 5.9 & -5.2 to 17.2 & 0.287 \\
\hline
\end{tabular}

low-up period showed a sustained large ES (0.80 and above) for both Physical and Mental health composite scores as well as for Emotional well-being. A medium ES (0.50-0.79) noted at 1-month follow-up which increased to a large ES at 3-month follow-up in the treatment group was demonstrated for the following domains: Physical role limitations, Emotional role limitations, Health perception and Social function. The overall quality of life domain score reached a large ES after 3 months. 
Table V. Quality of life change scores from baseline to third month

\begin{tabular}{|c|c|c|c|c|c|}
\hline MSQoL-54 & $\begin{array}{c}\text { Treatment }(N=17) \\
\text { mean } \pm \text { SD }\end{array}$ & $\begin{array}{c}\text { Control }(N=20) \\
\text { mean } \pm \text { SD }\end{array}$ & $\begin{array}{c}\text { Mean } \\
\text { difference }\end{array}$ & $\begin{array}{c}95 \% \mathrm{Cl} \text { for } \\
\text { mean difference }\end{array}$ & Value of $p$ \\
\hline Physical health & $+15.0 \pm 19.7$ & $+9.5 \pm 16.8$ & 5.5 & -6.7 to 17.7 & 0.366 \\
\hline $\begin{array}{l}\text { Physical role } \\
\text { limitations }\end{array}$ & $+33.8 \pm 38.59$ & $-0.1 \pm 42.1$ & 33.9 & 6.8 to 61.1 & 0.016 \\
\hline $\begin{array}{l}\text { Emotional role } \\
\text { limitations }\end{array}$ & $+31.4 \pm 36.3$ & $-5.2 \pm 43.6$ & 36.6 & 9.5 to 63.7 & 0.010 \\
\hline Pain & $+13.1 \pm 26.7$ & $+5.7 \pm 31.6$ & 7.4 & -12.3 to 27.1 & 0.452 \\
\hline $\begin{array}{l}\text { Emotional well- } \\
\text { being }\end{array}$ & $+15.1 \pm 15.3$ & $+7.4 \pm 22.4$ & 7.7 & -5.4 to 20.7 & 0.242 \\
\hline Energy & $+12.7 \pm 18.4$ & $+7.4 \pm 21.8$ & 5.3 & -8.1 to 18.7 & 0.434 \\
\hline Health perception & $+13.8 \pm 14.2$ & $+10.7 \pm 18.8$ & 3.1 & -8.2 to 14.3 & 0.584 \\
\hline Social function & $+17.2 \pm 13.9$ & $+9.6 \pm 19.5$ & 7.6 & -3.9 to 19.1 & 0.191 \\
\hline $\begin{array}{l}\text { Cognitive } \\
\text { functioning }\end{array}$ & $+2.1 \pm 13.6$ & $+6.0 \pm 21.8$ & -3.9 & -16.3 to 8.4 & 0.523 \\
\hline Health distress & $+10.9 \pm 22.9$ & $+11.2 \pm 18.4$ & -0.3 & -14.1 to 13.4 & 0.957 \\
\hline Sexual function & $+9.3 \pm 27.8$ & $+10.0 \pm 32.4$ & -0.7 & -21.0 to 19.7 & 0.946 \\
\hline Change in health & $-26.5 \pm 32.4$ & $-26.2 \pm 41.7$ & -0.3 & -25.5 to 25.1 & 0.986 \\
\hline $\begin{array}{l}\text { Sexual function } \\
\text { satisfaction }\end{array}$ & $+10.3 \pm 47.6$ & $+2.5 \pm 39.6$ & 7.8 & -21.3 to 36.9 & 0.590 \\
\hline $\begin{array}{l}\text { Overall quality } \\
\text { of life }\end{array}$ & $+11.6 \pm 14.4$ & $+2.7 \pm 13.5$ & 8.9 & -0.4 to 18.2 & 0.061 \\
\hline $\begin{array}{l}\text { Physical health } \\
\text { composite }\end{array}$ & $+15.9 \pm 10.2$ & $+8.1 \pm 14.2$ & 7.8 & -0.6 to 16.2 & 0.069 \\
\hline $\begin{array}{l}\text { Mental health } \\
\text { composite }\end{array}$ & $+16.2 \pm 12.6$ & $+3.8 \pm 16.5$ & 12.4 & 2.3 to 22.3 & 0.017 \\
\hline
\end{tabular}

In the control group, a sustained moderate ES was demonstrated only for Physical health composite and Health perception domain scores.

\section{Discussion}

In our study, we analyzed the benefits of administration of intravenous HDMP combined with MDR in 37 persons with RRMS in relapse, in order to assess whether combination of steroid therapy with MDR is more beneficial than steroid therapy alone, based on objective and patient-reported outcome data, including application of the MSQoL-54. Until now, to our best knowledge, only one randomized controlled trial has evaluated the benefits of planned MDR in combination with intravenous HDMP in the treatment of relapses, in persons with RRMS [22].

The EDSS and FIM motor scores, as disability measures, improved statistically significantly early after steroid therapy both in our treatment and control group, which is in line with previously published findings $[7,23]$. A significant improvement in $\mathrm{BDI}$ scores, relating to general depressive status, also occurred early after steroid treatment and was sustained for 3 months in MS patients treated with steroids and MDR, but no beneficial change was detected in our controls treated with HDMP only. It should also be mentioned that in our study no significant changes were detected in the EDSS, FIM and BDI scores, between baseline and 1-month and 3-month follow-up scores, comparing treatment and control groups. In contrast, in the above-mentioned randomized study, which included 20 subjects in each group (MS patients treated with HDMP and MDR and those treated with HDMP and standard care), findings demonstrated significant differences in both the Guys Neurological Disability Scale [24] and the Barthel Index [25] at 3 months in favor of HDMP combined with MDR [22]. However, additionally, the authors assessed QoL using a generic questionnaire, the Short Form 36 Health Survey (SF-36) [26], and analysis of change of scores in various domains from baseline to month 3 did not show any significance, except for the Social Function domain, which indicated a trend towards significance.

Regarding patient-reported outcome, in our study in which we used the disease-specific questionnaire MSQoL-54, in contrast, a statistically sig- 
Table VI. Mean quality of life scores at baseline and at follow-ups and effect sizes in comparison with those at baseline in treatment and control group

\begin{tabular}{|c|c|c|c|c|}
\hline \multicolumn{2}{|l|}{ MSQoL-54 } & At baseline & After 1-month follow-up & After 3-month follow-up \\
\hline \multicolumn{5}{|c|}{ Physical health: } \\
\hline \multirow[t]{2}{*}{ Treatment } & Score & $52.9(24.3)$ & $67.1(23.3)^{\star}$ & $67.9(22.8)^{* \star}$ \\
\hline & ES & & $0.56(0.04,1.07)$ & $0.76(0.24,1.27)$ \\
\hline \multirow[t]{2}{*}{ Control } & Score & $50.5(25.7)$ & $64.0(24.9)^{\star *}$ & $60.0(27.1)^{\star}$ \\
\hline & ES & & $0.83(0.35,1.30)$ & $0.56(0.09,1.03)$ \\
\hline \multicolumn{5}{|c|}{ Physical role limitations: } \\
\hline \multirow[t]{2}{*}{ Treatment } & Score & $25.5(36.9)$ & $52.9(44.9)^{\star *}$ & $57.3(43.9)^{\star \star}$ \\
\hline & ES & & $0.72(0.20,1.23)$ & $0.88(0.36,1.39)$ \\
\hline \multirow[t]{2}{*}{ Control } & Score & $37.6(38.5)$ & $35.0(43.2)$ & $37.5(46.2)$ \\
\hline & ES & & $-0.07(-0.54,0.39)$ & $-0.11(-19.83,19.61)$ \\
\hline \multicolumn{5}{|c|}{ Emotional role limitations: } \\
\hline \multirow[t]{2}{*}{ Treatment } & Score & $41.1(44.9)$ & $64.7(41.6)^{\star \star}$ & $72.5(41.2)^{\star \star}$ \\
\hline & ES & & $0.52(0.01,1.05)$ & $0.86(0.35,1.38)$ \\
\hline \multirow[t]{2}{*}{ Control } & Score & $51.9(44.9)$ & $55.0(44.9)$ & $46.7(45.1)$ \\
\hline & ES & & $0.07(-0.39,0.54)$ & $-0.11(-0.59,0.34)$ \\
\hline \multicolumn{5}{|l|}{ Pain: } \\
\hline \multirow[t]{2}{*}{ Treatment } & Score & $49.6(30.9)$ & $64.4(31.9)^{\star *}$ & $62.7(31.9)$ \\
\hline & ES & & $1.13(0.61,1.64)$ & $0.49(-0.02,1.00)$ \\
\hline \multirow[t]{2}{*}{ Control } & Score & $46.3(29.5)$ & $56.7(30.5)$ & $52.1(29.7)$ \\
\hline & ES & & $0.41(-0.06,0.88)$ & $0.18(-0.29,0.65)$ \\
\hline \multicolumn{5}{|c|}{ Emotional well-being: } \\
\hline \multirow[t]{2}{*}{ Treatment } & Score & $50.8(26.6)$ & $66.5(20.3)^{\star \star}$ & $65.9(18.7)^{\star \star}$ \\
\hline & ES & & $0.83(0.31,1.34)$ & $0.98(0.46,1.50)$ \\
\hline \multirow[t]{2}{*}{ Control } & Score & $53.6(18.9)$ & $64.2(17.8)^{\star}$ & $61.0(22.5)$ \\
\hline & ES & & $0.48(0.01,0.94)$ & $0.32(-0.13,0.80)$ \\
\hline \multicolumn{5}{|l|}{ Energy: } \\
\hline \multirow[t]{2}{*}{ Treatment } & Score & $47.3(23.8)$ & $55.8(23.4)^{\star}$ & $60.0(25.0)^{\star *}$ \\
\hline & ES & & $0.58(0.07,1.10)$ & $0.69(0.17,1.20)$ \\
\hline \multirow[t]{2}{*}{ Control } & Score & $41.0(18.4)$ & $52.0(16.5)^{\star}$ & $48.4(23.8)$ \\
\hline & ES & & $0.53(0.07,1.00)$ & $0.33(-0.13,0.80)$ \\
\hline \multicolumn{5}{|c|}{ Health perception: } \\
\hline \multirow[t]{2}{*}{ Treatment } & Score & $42.9(29.3)$ & $47.9(22.4)^{\star}$ & $56.8(22.8)^{\star \star}$ \\
\hline & ES & & $0.53(0.01,1.03)$ & $0.97(0.46,1.49)$ \\
\hline \multirow[t]{2}{*}{ Control } & Score & $35.7(13.2)$ & $46.7(18.9)^{\star *}$ & $46.5(21.5)^{\star}$ \\
\hline & ES & & $0.70(0.22,1.16)$ & $0.57(0.10,1.04)$ \\
\hline \multicolumn{5}{|c|}{ Social function: } \\
\hline \multirow[t]{2}{*}{ Treatment } & Score & $53.9(25.4)$ & $65.7(20.6)^{\star *}$ & $71.08(22.9)^{\star *}$ \\
\hline & ES & & $0.72(0.20,1.23)$ & $1.23(0.71,1.74)$ \\
\hline Control & Score & $58.3(21.4)$ & $66.2(23.8)$ & $67.9(25.1)^{*}$ \\
\hline & ES & & $0.41(-0.05,0.88)$ & $0.49(0.02,0.96)$ \\
\hline Cognitive fun & & & & \\
\hline Treatment & Score & $68.5(25.2)$ & $72.6(20.5)$ & $72.9(24.2)$ \\
\hline & ES & & $0.21(-0.30,0.73)$ & $0.10(-0.26,0.47)$ \\
\hline Control & Score & $68.5(28.6)$ & $77.0(21.7)$ & $74.5(26.1)$ \\
\hline & ES & & $0.40(-0.06,0.87)$ & $0.28(-0.19,0.74)$ \\
\hline
\end{tabular}


Table VI. Cont.

\begin{tabular}{|c|c|c|c|c|}
\hline \multicolumn{2}{|l|}{ MSQoL-54 } & At baseline & After 1-month follow-up & After 3-month follow-up \\
\hline \multicolumn{5}{|c|}{ Health distress: } \\
\hline \multirow{2}{*}{ Treatment } & Score & $62.3(24.3)$ & $63.8(24.4)$ & $73.2(24.5)$ \\
\hline & ES & & $0.09(-0.41,0.61)$ & $0.48(-0.04,0.99)$ \\
\hline \multirow[t]{2}{*}{ Control } & Score & $54.0(20.6)$ & $58.7(23.8)$ & $65.2(23.3)$ \\
\hline & ES & & $0.19(-0.27,0.66)$ & $0.61(0.14,1.08)$ \\
\hline \multicolumn{5}{|c|}{ Sexual function: } \\
\hline \multirow[t]{2}{*}{ Treatment } & Score & $51.9(33.7)$ & $48.5(32.8)$ & $61.3(32.5)$ \\
\hline & ES & & $-0.14(-0.66,0.37)$ & $0.33(-0.18,0.85)$ \\
\hline \multirow[t]{2}{*}{ Control } & Score & $59.2(36.2)$ & $63.3(41.9)$ & $69.1(37.5)$ \\
\hline & ES & & $0.14(-0.32,0.61)$ & $0.30(-0.16,0.78)$ \\
\hline \multicolumn{5}{|c|}{ Change in health: } \\
\hline \multirow[t]{2}{*}{ Treatment } & Score & $51.5(16.5)$ & $38.2(29.5)$ & $25.0(34.2)^{\star \star}$ \\
\hline & ES & & $-0.43(-0.94,0.08)$ & $-0.81(-1.33,-0.30)$ \\
\hline \multirow[t]{2}{*}{ Control } & Score & $52.5(22.8)$ & $37.5(29.8)$ & $26.3(32.9)^{\star *}$ \\
\hline & ES & & $-0.37(-0.84,0.09)$ & $-0.62(-1.09,-0.16)$ \\
\hline \multicolumn{5}{|c|}{ Sexual function satisfaction: } \\
\hline \multirow[t]{2}{*}{ Treatment } & Score & $50.0(29.3)$ & $50.0(20.5)$ & $60.3(33.1)$ \\
\hline & ES & & $0.00(-0.51,0.51)$ & $0.21(-0.29,0.73)$ \\
\hline \multirow[t]{2}{*}{ Control } & Score & $50.0(29.2)$ & $42.5(33.5)$ & $52.5(27.9)$ \\
\hline & ES & & $-0.16(-0.63,0.30)$ & $0.06(-0.41,0.53)$ \\
\hline \multicolumn{5}{|c|}{ Overall quality of life: } \\
\hline \multirow[t]{2}{*}{ Treatment } & Score & $51.8(17.3)$ & $59.6(17.8)$ & $63.3(17.4)^{\star *}$ \\
\hline & ES & & $0.47(-0.04,0.99)$ & $0.80(0.29,1.31)$ \\
\hline \multirow[t]{2}{*}{ Control } & Score & $50.0(13.9)$ & $54.0(18.1)$ & $52.7(20.4)$ \\
\hline & ES & & $0.32(-0.14,0.79)$ & $0.20(-0.27,0.66)$ \\
\hline \multicolumn{5}{|c|}{ Physical health composite: } \\
\hline \multirow[t]{2}{*}{ Treatment } & Score & $47.7(19.8)$ & $58.4(21.1)^{\star \star}$ & $63.7(22.4)^{\star \star}$ \\
\hline & ES & & $1.05(0.53,1.56)$ & $1.55(1.03,2.07)$ \\
\hline \multirow[t]{2}{*}{ Control } & Score & $46.9(17.2)$ & $54.9(17.6)^{\star \star}$ & $55.0(20.8)^{*}$ \\
\hline & ES & & $0.72(0.26,1.20)$ & $0.57(0.10,1.04)$ \\
\hline \multicolumn{5}{|c|}{ Mental health composite: } \\
\hline \multirow[t]{2}{*}{ Treatment } & Score & $52.9(23.8)$ & $65.4(20.6)^{\star \star}$ & $69.1(21.7)^{\star \star}$ \\
\hline & ES & & $0.88(0.37,1.39)$ & $1.29(0.77,1.80)$ \\
\hline \multirow[t]{2}{*}{ Control } & Score & $54.8(19.7)$ & $61.3(19.5)$ & $58.7(20.3)$ \\
\hline & ES & & $0.35(-0.12,0.81)$ & $0.23(-0.24,0.70)$ \\
\hline
\end{tabular}

ES - effect size $\left({ }^{*} p<0.05,{ }^{* *} p<0.01\right)$. Scores are presented with mean value and standard deviation in parenthesis, and ES with $95 \%$ confidence intervals. Negative values for ES represent decline in quality of life.

nificant improvement in HRQoL in the treatment group both 1 and 3 months after baseline was detected for the following scales of MSQoL-54: Physical health, Physical role limitations, Emotional role limitations, Emotional well-being, Energy, Health perception, Social function, as well as for both Physical health composite and Mental health composite, as presented in Table VI. In the control group, significant improvement in quality of life domains was demonstrated at both time points only for Physical health, Health perception and for Physical health composite.

Furthermore, in order to assess the magnitude of differences for the quality of life, the ES was calculated, and in the treatment group the analysis of magnitude for changes in HRQoL during the entire follow-up period showed a sustained large ES ( 0.80 and above) for both Physical and Mental health composite scores as well as for Emotional well-being. The medium ES (0.50-0.79) registered 
at month 1 which increased to a large ES at month 3 in the treatment group was demonstrated for the following domains: Physical role limitations, Emotional role limitations, Health perception and Social function. The overall quality of life domain score reached a large ES after 3 months. In the control group, only a moderate sustained ES was demonstrated for Physical health composite and Health perception domain scores.

As already mentioned, the study of HDMP treatment in relapses by Bethoux et al. revealed that neurological improvements occurred early after steroids [7]. However, this investigation demonstrated that quality of life changes were delayed; namely, significant improvement according to the Mental Health Inventory and MS-related Symptom Checklist occurred between 4 and 12 weeks after initiation of HDMP [7]. On the other hand, improvements in SF-36 physical and mental composite scores did not reach statistical significance. Therefore, the authors concluded that rehabilitative interventions are potentially warranted options for reducing overall MS burden.

Our results imply that rehabilitation affects various aspects of the persons' lives related to both physical and emotional domains. They strongly support the notion that comprehensive MDR during steroid treatment of MS relapse is beneficial in terms of improving disability and various aspects of HRQoL. Furthermore, it is important that MDR should include effective communication, coordination of management and patient education. All these data have to be emphasized in order to increase the significance of rehabilitation as an important treatment option for MS patients, including those in relapse, both by physicians and patients.

Certain methodological limitations of this study as well as the existence of psychological factors and education degree of our patients which could have influenced MSQoL-54 domains need to be mentioned. The study was performed in a single center, and therefore included a relatively small number of subjects, with non-blinded assessors. The follow-up period could have been longer, especially in order to allow more appropriate evaluation of long-term effects of intervention. In this study we did not analyze the effect of depression as a potential confounding factor in assessment of quality of life, although it is generally accepted that depression appears to be the major factor influencing HRQoL $[27,28]$. Additionally, until now, the prognostic value of education level on the HRQoL has been demonstrated in several studies $[27,29]$. A higher level of education was a significant prognostic factor for a better quality of life. These findings could be explained as follows: a higher level of education may lead to a stronger awareness regarding the disease, and reflect a better ability to cope with the challenges of a chronic disorder such as MS. Moreover, a higher level of education could be indirectly associated with a better HRQoL due to a higher standard of living. However, in our study, there was no significant difference in educational level between our treatment and control group, and, therefore, we did not analyze the influence of educational degree of our subjects on outcome.

In conclusion, our results provide further support for the notion that combination of MDR with intravenous HDMP could be beneficial in the treatment of acute relapses of MS, since MDR seems to be effective in improving quality of life after relapse.

\section{Acknowledgments}

This work was supported by the Ministry of Education and Science of the Republic of Serbia (grant numbers 175031 and 175087).

\section{Conflict of interest}

The authors declare no conflict of interest.

\section{References}

1. Ontaneda D, Hyland M, Cohen JA. Multiple sclerosis: new insights in pathogenesis and novel therapeutics. Annu Rev Med 2012; 63: 389-404.

2. Multiple Sclerosis Therapy Consensus Group (MSTCG). Basic and escalating immunomodulatory treatments in multiple sclerosis: current therapeutic recommendations. J Neurol 2008; 255: 1449-63.

3. Filipovic SR, Drulovic J, Stojsavljevic N, Levic Z. The effects of high-dose intravenous methylprednisolone on event-related potentials in patients with multiple sclerosis. J Neurol Sci 1997; 152: 147-53.

4. Goodin DS. Glucocorticoid treatment of multiple sclerosis. Handb Clin Neurol 2014; 122: 455-64.

5. Piri Cinar B, Ozakbas S, Idiman E. Evaluation of clinical parameters during and after treatment of attack in patients with clinically isolated syndrome: comparison of the results with that of multiple sclerosis patients. Clin Neurol Neurosurg 2013; 115: 2432-7.

6. Lublin FD, Baier M, Cutter G. Effect of relapses on development of residual deficit in multiple sclerosis. Neurology 2003; 61: 1528-32.

7. Bethoux F, Miller DM, Kinkel RP. Recovery following acute exacerbations of multiple sclerosis: from impairment to quality of life. Mult Scler 2001; 7: 137-42.

8. Myhr KM, Mellgren SI. Corticosteroids in the treatment of multiple sclerosis. Acta Neurol Scand Suppl 2009; 189: 73-80.

9. Motl RW, Arnett PA, Smith MM, Barwick FH, Ahlstrom B, Stover EJ. Worsening of symptoms is associated with lower physical activity levels in individuals with multiple sclerosis. Mult Scler 2008; 14: 140-2.

10. Beer S, Khan F, Kesselring J. Rehabilitation interventions in multiple sclerosis: an overview. J Neurol 2012; 259: 1994-2008.

11. Motl RW, McAuley E, Snook EM. Physical activity and multiple sclerosis: a meta-analysis. Mult Scler 2005; 11: 459-63. 
12. Khan F, Pallant JF, Brand C, Kilpatrick TJ. Effectiveness of rehabilitation intervention in persons with multiple sclerosis: a randomised controlled trial. J Neurol Neurosurg Psychiatry 2008; 79: 1230-5.

13. Ulubay G, Ulasli SS, Bozbas SS, Ozdemirel T, Karatas M. Effects of peripheral neuropathy on exercise capacity and quality of life in patients with chronic obstructive pulmonary diseases. Arch Med Sci 2012; 8: 296-302.

14. Liu C, Playford ED, Thompson AJ. Does neurorehabilitation have a role in relapsing-remitting multiple sclerosis? J Neurol 2003; 250: 1214-8.

15. Polman CH, Reingold SC, Edan G, et al. Diagnostic criteria for multiple sclerosis: 2005 revisions to the "McDonald Criteria". Ann Neurol 2005; 58: 840-6.

16. Granger CV, Cotter AC, Hamilton BB, Fiedler RC, Hens MM. Functional Assessment Scales: study of persons of multiple sclerosis. Arch Phys Med Rehabil 1990; 71: 870-5.

17. Kurtzke JF. Rating neurologic instrument in multiple sclerosis: an expanded disability status scale (EDSS). Neurology 1983; 33: 1444-52.

18. Beck AT, Beck RW. Screening depressed patients in family practice: a rapid technique. Postgrad Med 1972; 52: 81-5.

19. Pekmezovic T, Kisic Tepavcevic D, Kostic J, Drulovic J. Validation and cross-cultural adaptation of the disease-specific questionnaire MSQoL-54 in Serbian multiple sclerosis patients sample. Qual Life Res 2007; 16: 1383-7.

20. Likert RA. A technique for the development of attitudes. Arch Psychol 1932; 140: 5-55.

21. Cohen J. Statistical power analysis for the behavioral sciences. Academic Press, New York 1988.

22. Craig J, Young CA, Ennis M, Baker G, Boggild M. A randomized controlled trial comparing rehabilitation against standard therapy in multiple sclerosis patients receiving intravenous steroid treatment. J Neurol Neurosurg Psychiatry 2003; 74: 1225-30.

23. Miller DM, Weinstock-Guttman B, Béthoux F, et al. A meta-analysis of methylprednisolone in recovery from multiple sclerosis exacerbations. Mult Scler 2000; 6: 267-73.

24. Paltamaa J, West H, Sarasoja T, Wikstrom J, Malkia E. Reliability of physical functioning measures in ambulatory subjects with multiple sclerosis. Physiother Res Int 2005; 10: 93-109.

25. Mahoney FI, Barthel DW. Functional evaluation: the Barthel index. Md State Med J 1965; 14: 61-5.

26. Ware JE, Snow KK, Kosinski M. SF-36 health survey: manual and interpretation guide. The Health Institute, New England Medical Center, Boston 1993.

27. Kisic Tepavcevic D, Pekmezovic T, Stojsavljevic N, et al. Change in quality of life and predictors of change among patients with multiple sclerosis: a prospective cohort study. Qual Life Res 2014; 23: 1027-37.

28. Klevan G, Jacobsen CO, Aarseth JH, et al. Health related quality of life in patients recently diagnosed with multiple sclerosis. Acta Neurol Scand 2014; 129: 21-6.

29. Hopman WM, Coo H, Pavlov A, et al. Multiple sclerosis: change in health-related quality of life over two years. Can J Neurol Sci 2009; 36: 554-61. 